\title{
A survey of the antidote preparedness in Norwegian hospitals
}

Authors

Yvonne Elisabeth $\mathrm{Lao}^{1,2^{*}}$

Anne Goffeng ${ }^{3}$

Barbro Johanne Spillum ${ }^{4}$

Dag Jacobsen 3,5

Espen Rostrup Nakstad ${ }^{1}$

Knut Erik Hovda ${ }^{1}$

${ }^{1}$ Norwegian National Unit for CBRNE Medicine, Department of Acute Medicine, Oslo University Hospital, Oslo, Norway

${ }^{2}$ Oslo Hospital Pharmacy, Hospital Pharmacy Enterprise, Oslo, Norway

${ }^{3}$ Faculty of Medicine, Institute of Clinical Medicine, University of Oslo, Oslo, Norway

${ }^{4}$ Norwegian Poison Information Centre, Norwegian Institute of Public Health, Oslo, Norway

${ }^{5}$ Department of Acute Medicine, Oslo University Hospital, Oslo, Norway

*Corresponding author:

Yvonne Lao

Norwegian National Unit for CBRNE Medicine, Department of Acute Medicine,

Oslo University Hospital, Ullevaal

P.O.Box 4956 Nydalen,

0424 Oslo

Norway

Email:yvonne.lao@sykehusapotekene.no

Word count: 2424 


\section{Objectives}

Antidotes are an important part of the emergency preparedness in hospitals. In case of a major chemical accident or a fire, large amounts of antidotes may be needed within a short period of time. For time-critical antidotes it is therefore necessary that they are immediately available. We wanted to evaluate the antidote preparedness in Norwegian hospitals towards the national recommendations and compare this with other international guidelines.

\section{Methods}

A digital survey was sent to the 50 hospitals in Norway treating acute poisonings. There were 4 hospitals categorized as regional hospital, 15 as large hospitals and 31 as small hospitals. Each hospital was asked which antidotes they stockpiled from a list of 35 . The financial cost (low, moderate, high) were added to an established efficacy scale to illustrate cost effectiveness of the different antidotes.

\section{Results}

The response rate was $100 \%$. Eleven out of fifty hospitals (22\%) stockpiled all antidotes recommended for their hospital size. All four regional hospitals had all the recommended antidotes. Large hospitals which were not regional hospitals had the least availability of antidotes, and only one large hospital stockpiled all antidotes recommended for this hospital size.

\section{Conclusions}

We found a varying compliance with the national recommendations for antidote storage in hospitals. To strengthen antidote preparedness, we recommend standardized European guidelines to support national guidelines.

Key word: emergency medicine, critical care, clinical medicine, quality of health care, management audit 


\section{Key message}

What is already known on this subject

- Insufficient stocking of antidotes in hospital is well known.

- Lack of guidelines is suggested as one possible cause.

- There are no European guidelines for antidote stocking.

What does this study adds

- Norwegian hospitals are not compliant with national recommendations for stockpiling of antidotes in hospitals.

- Recommendations based on urgency of availability is preferable to hospital size. 


\section{BACKGROUND}

Combined with supportive care, antidotes are cornerstones in the treatment for poisonings. They are also important elements in chemical and radiological incident preparedness. Some medical conditions require immediate availability, for other conditions antidotes are not considered time-critical for adequate treatment. In recent years, there has been an increased focus on preparedness for chemical incidents, for example caused by industrial accidents or terror attacks ${ }^{1,2}$.

Studies from different countries have shown insufficient stocking of antidotes ${ }^{3-8}$. Lack of guidelines have been proposed as one possible cause ${ }^{3,7}$. In 1997 the International Programme on Chemical Safety (IPCS) published a list of antidotes considered useful in the treatment of poisoning and classified them according to the urgency of availability ${ }^{9}$. Consensus guidelines for stockpiling of emergency antidotes in The United States (US) followed in $2000^{10}$, and were updated in $2009^{11}$ and $2018^{12}$. These guidelines were also classified in relation to their urgency for availability. Similar guidelines exist for The United Kingdom (UK $)^{13}$. There is no European consensus for this and each country has to make their own guidelines.

In 2000, Solheim et al. conducted a survey to describe the antidote preparedness situation in Norway ${ }^{14}$. They concluded that the antidote preparedness was not satisfactory and that guidelines were lacking. They recommended a list of antidotes which should be available in hospitals based on the hospital size. In 2007, the Norwegian Poison Information Centre published national recommendations for antidote stocking in hospitals: These recommendations were divided in three groups: 1) recommendations for all hospitals, 2) recommendations for large hospitals and 3) recommendations for regional hospitals (Table 1). Current recommendations are still categorized in these groups and recommended antidotes are continuously updated. There are no minimum quantities recommended, only an estimate on the amount needed to treat one patient $(70 \mathrm{~kg})$. No follow-up study has been made after the publication of these recommendations.

Our aim was to describe the antidote preparedness in Norway according to the national recommendations and compare this model towards other strategies found internationally. Since the costs of antidote preparedness may be a limiting factor, we wanted to discuss the element of cost versus effect. 
Table 1: Recommendations for antidote stocking in Norwegian hospitals

\begin{tabular}{|l|l|l|}
\hline Recommended in all hospitals & $\begin{array}{l}\text { Additional recommendations } \\
\text { for large- and regional } \\
\text { hospitals }\end{array}$ & $\begin{array}{l}\text { Additional recommendations } \\
\text { for regional hospitals }\end{array}$ \\
\hline Acetylcysteine & Calcium folinate injection & DMPS $^{\text {a }}$ \\
\hline Activated charcoal & Cyproheptadine & DMSA $^{\text {b }}$ \\
\hline Atropine & Dantrolene & Penicillamine \\
\hline Biperiden & Deferoxamine & Prussian blue \\
\hline Calcium gluconate (local and IV) & Digoxin immune FAB (DigiFab ${ }^{\circledR}$ ) & Sodium calcium edetate \\
\hline Ethanol IV & Fomepizole & \\
\hline Flumazenil & Methylthionium chloride & \\
\hline Glucagon & Obidoxime & \\
\hline Hydroxocobalamin & Octreotide & \\
\hline Ipecac syrup & Pyridoxine injection & \\
\hline Lipid emulsion & Silibinin & \\
\hline Naloxone & Sodium thiosulfate & \\
\hline Physostigmine & $\begin{array}{l}\text { Vipera berus antivenom } \\
\text { (ViperaTAb }\end{array}$ & \\
\hline Phytomenadione & & \\
\hline Protamine sulfate & & \\
\hline Sodium sulfate & & \\
\hline
\end{tabular}

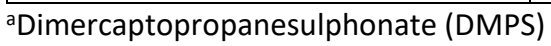

${ }^{b}$ Dimercaptosuccinic acid (DMSA)

\section{METHOD}

A digital survey was conducted among all hospitals treating acute poisonings in Norway $(\mathrm{N}=50)$. These are all public hospitals, as the few private ones that exist only have elective function. The survey was sent to the nurse or the doctor who followed up the antidote storage. In hospitals where the hospital pharmacy had the daily responsibility for the follow up, the survey was sent to a hospital pharmacist. Norway is a sparsely inhabited country with some areas having a long distance between hospitals. The organization of them is therefore a hierarchy of hospitals in each health region and local hospital thrust instead of number of beds. There are a total of six University hospitals and four health regions. We defined a regional hospital as the largest University hospital in each of the four health regions. Each health region has several local hospital thrusts and a large hospital was defined as the hospital with the largest hospital catchment population in each local hospital thrust. Other hospitals were categorised as small. A total of 31 hospitals were categorised as small, 15 as large and four as regional. An email with a link to the survey was sent in April 2016. After two email reminders, hospitals were contacted by phone until the survey was closed in June 2016. Each hospital was asked whether they had an antidote storage, the availability from a list of 35 antidotes (Table 1), in which quantities, and when the content was last revised. If a product was not a part of the antidote storage they were asked whether it was available in another location at the hospital. The national recommendations 
also include drugs which are used routinely at hospitals for other indications, for example norepinephrine and insulin. These were not included in the survey. We also asked about the availability of diethylenetriamine pentaacetate (DTPA) for binding of radioactive plutonium, americium and curium ${ }^{15}$, as part of the preparedness against radiation emergencies. This was not included in our national recommendations, but is recommended to stockpile by World Health Organization ${ }^{16}$. Some antidotes are not relevant in all regions, e.g. vipera berus antivenom where there are no vipers or silibinin where there are no relevant mushrooms. This was all corrected for in our data processing.

To assess the cost of treating a poisoning case with antidote, the cost of one $70 \mathrm{~kg}$ patient was calculated. This was based on the estimated amounts in the national recommendations. We chose to divide the costs in three groups; low (<300 Euro), moderate (300-1000 Euro) and high ( $>1000$ Euro). The costs are calculated from prices from October 2018.

\section{RESULTS}

All 50 hospitals responded to the survey. Half (54\%) of the hospitals had revised their antidote list after January 2015, $14 \%$ between 2012 and 2014, $6 \%$ before 2012 and $26 \%$ did not know when it was last revised.

There were 11 of 50 (22\%) hospitals which stored all antidotes recommended for their hospital size. All four regional hospitals were fully compliant with the recommendations, and 1/15 (7\%) of large hospitals. For small hospitals the corresponding number was 6/31 (19\%). Further, some small hospitals chose to have fomepizole instead of intravenous (IV) ethanol and some had pralidoxime instead of obidoxime; both of which was considered adequate.

Table 2 shows the availability of each antidote. Cyproheptadine for serotonergic syndrome was the antidote which was least available in large hospital and sodium sulphate against barium poisoning was the least available antidote in small hospitals. Only one hospital stockpiled DTPA for internal contamination with radioactive plutonium, americium and curium. 
Table 2: Availability of antidotes in Norwegian hospitals

\begin{tabular}{|c|c|c|c|c|c|}
\hline Antidote & $\begin{array}{l}\text { Hospitals } \\
(\%) \\
N=50\end{array}$ & $\begin{array}{l}\text { Hospital which } \\
\text { can give full } \\
\text { treatment to at } \\
\text { least one } 70 \mathrm{~kg} \\
\text { patient } \\
(\%) \\
\mathrm{N}=50\end{array}$ & $\begin{array}{l}\text { Regional hospital } \\
\text { following } \\
\text { recommendation } \\
(\%) \\
\mathrm{N}=4\end{array}$ & $\begin{array}{l}\text { Large hospitals } \\
\text { following } \\
\text { recommendation } \\
(\%) \\
N=15\end{array}$ & $\begin{array}{l}\text { Small hospitals } \\
\text { following } \\
\text { recommendation } \\
\text { (\%) } \\
\mathrm{N}=31\end{array}$ \\
\hline Acetylcysteine & $50(100)$ & $45(90)^{a}$ & $4(100)$ & $15(100)$ & $31(100)$ \\
\hline Activated charcoal & $50(100)$ & $27(54)^{a, b}$ & $4(100)$ & $15(100)$ & $31(100)$ \\
\hline Atropine & $50(100)$ & $50(100)^{c}$ & $4(100)$ & $15(100)$ & $31(100)$ \\
\hline Biperiden & $49(98)$ & $49(98)^{c}$ & $4(100)$ & $15(100)$ & $30(97)$ \\
\hline Calcium folinate injection & $36(72)$ & $1(2)^{\mathrm{a}}$ & $4(100)$ & $13(87)$ & $19^{d}$ \\
\hline Calcium gluconate injection & $47(94)$ & $47(94)^{c}$ & $4(100)$ & $15(100)$ & $28(90)$ \\
\hline $\begin{array}{l}\text { Calcium gluconate local } \\
\text { treatment }\end{array}$ & $48(96)$ & $48(96)^{c}$ & $4(100)$ & $15(100)$ & $29^{d}$ \\
\hline Cyproheptadine & $8(16)$ & $8(16)^{c}$ & $4(100)$ & $4(27)$ & $0^{d}$ \\
\hline Dantrolene & $49(98)$ & $1(2)^{a, b}$ & $4(100)$ & $15(100)$ & $30^{d}$ \\
\hline Deferoxamine & $44(88)$ & $21(42)^{a, b}$ & $4(100)$ & $14(93)$ & $26^{d}$ \\
\hline $\begin{array}{l}\text { Digoxin immune FAB } \\
\text { (DigiFab }^{\circledR} \text { ) }\end{array}$ & $17(34)$ & $13(26)^{\mathrm{a}, \mathrm{b}}$ & $4(100)$ & $7(47)$ & $6^{d}$ \\
\hline DMPS (IV or orally) & $12(24)$ & $4(8)^{a, b}$ & $4(100)$ & $5^{d}$ & $3^{d}$ \\
\hline$D M^{f} A^{f}$ & $6(12)$ & $5(10)^{a}$ & $4(100)$ & $1^{\mathrm{d}}$ & $1^{d}$ \\
\hline DTPA $^{g}$ & $1(2)$ & $1(2)^{c}$ & $1^{\mathrm{d}}$ & $0^{d}$ & $0^{d}$ \\
\hline Ethanol IV & $45(90)$ & $28(56)^{\mathrm{a}, \mathrm{b}}$ & $4(100)$ & $14(93)$ & $27(87)$ \\
\hline Flumazenil & $50(100)$ & $34(68)^{a, b}$ & $4(100)$ & $15(100)$ & $31(100)$ \\
\hline Fomepizole & $32(64)$ & $12(24)^{a, b}$ & $4(100)$ & $14(93)$ & $14^{\mathrm{d}}$ \\
\hline Glucagon & $43(86)$ & $29(58)^{a, b}$ & $4(100)$ & $13(87)$ & $26(84)$ \\
\hline Hydroxocobalamin & $45(90)$ & $32(64)^{a, b}$ & $4(100)$ & $15(100)$ & $26(84)$ \\
\hline Ipecac syrup & $49(98)$ & $49(98)^{c}$ & $4(100)$ & $15(100)$ & $30(97)$ \\
\hline Lipid emulsion & $48(96)$ & $37(74)^{\mathrm{a}}$ & $4(100)$ & $13(87)$ & $31(100)$ \\
\hline Methylthionium chloride & $36(72)$ & $19(38)^{a, b}$ & $4(100)$ & $13(87)$ & $19^{d}$ \\
\hline Naloxone & $50(100)$ & $50(100)^{c}$ & $4(100)$ & $15(100)$ & $31(100)$ \\
\hline Obidoxime & $27(54)$ & $27(54)^{c}$ & $3(75)$ & $12(80)$ & $12^{\mathrm{d}}$ \\
\hline Octreotide & $40(80)$ & $40(80)^{c}$ & $4(100)$ & $14(93)$ & $22^{d}$ \\
\hline Penicillamine & $7(14)$ & $7(14)^{c}$ & $4(100)$ & $3^{d}$ & $0^{d}$ \\
\hline Physostigmine & $48(96)$ & $48(96)^{a}$ & $4(100)$ & $15(100)$ & $29(94)$ \\
\hline Phytomenadione & $50(100)$ & $47(94)^{a}$ & $4(100)$ & $15(100)$ & $31(100)$ \\
\hline Protamine sulfate & $44(88)$ & $44(88)^{c}$ & $4(100)$ & $14(93)$ & $26(84)$ \\
\hline Prussian blue & $5(10)$ & $4(8)^{a}$ & $4(100)$ & $1^{\mathrm{d}}$ & $0^{d}$ \\
\hline Pyridoxine injection & $25(50)$ & $25(50)^{c}$ & $4(100)$ & $13(87)$ & $8^{d}$ \\
\hline Silibinin & $18(36)$ & $7(14)^{a, b}$ & $4(100)$ & $10(71)^{\mathrm{h}}$ & $4^{d}$ \\
\hline Sodium calcium edetate & $11(22)$ & $4(8)^{a, b}$ & $4(100)$ & $3^{d}$ & $4^{d}$ \\
\hline Sodium sulfate & $18(36)$ & $10(20)^{a, b}$ & $4(100)$ & $6(40)$ & $8(26)$ \\
\hline Sodium thiosulfate & $43(86)$ & $18(36)^{a, b}$ & $4(100)$ & $15(100)$ & $24^{d}$ \\
\hline 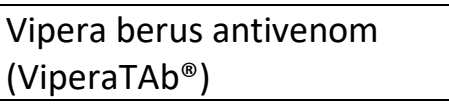 & $25(50)$ & $25(50)^{c}$ & $3(100)^{h}$ & $10(71)^{\mathrm{h}}$ & $12^{\mathrm{h}}$ \\
\hline
\end{tabular}

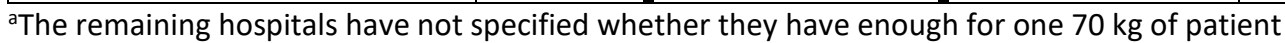

${ }^{\mathrm{b}}$ The remaining hospitals have specified that they do not have enough for $70 \mathrm{~kg}$ of patient

cAll hospitals have verified that they have enough for one $70 \mathrm{~kg}$ patient

dNot recommended for this hospital size

eDimercaptopropanesulphonate (DMPS)

fDimercaptosuccinic acid (DMSA)

${ }^{g}$ Diethylenetriamine pentaacetate (DTPA)

${ }^{\text {h}}$ Corrected for regions where there are no vipers or relevant mushrooms 
Table 3 shows the cost for treatment of one $70 \mathrm{~kg}$ patient. Figure 1 is an updated version of IPCS's efficacy scale of important and commonly used antidotes ${ }^{17}$, with cost added to create a cost /efficacy scale.

Table 3: Price category for antidote treatment for one $70 \mathrm{~kg}$ patient based on national recommendations

\begin{tabular}{|c|c|}
\hline Antidote & $\begin{array}{l}\text { Cost } \\
\text { Low: < } 300 \text { Euro } \\
\text { Moderate: } 300-1000 \text { Euro } \\
\text { High }>1000 \text { Euro }\end{array}$ \\
\hline Acetylcysteine & Low \\
\hline Activated charcoal & Low \\
\hline Atropine & Low \\
\hline Biperiden & Low \\
\hline Calcium folinate injection & High \\
\hline Calcium gluconate IV treatment & Low \\
\hline Calcium gluconate local treatment & Low \\
\hline Cyproheptadine & Low \\
\hline Dantrolene & High \\
\hline Deferoxamine & Low \\
\hline Digoxin immune FAB $\left(\right.$ DigiFab $\left.^{\circledR}\right)$ & High \\
\hline DMPS $^{a}$ & Moderate \\
\hline DMSA $^{b}$ & High \\
\hline Ethanol IV & High \\
\hline Flumazenil & Low \\
\hline Fomepizole & High \\
\hline Glucagon & Moderate \\
\hline Hydroxocobalamin & High \\
\hline Ipecac syrup & Low \\
\hline Lipid emulsion & Low \\
\hline Methylthionium chloride & Moderate \\
\hline Naloxone & Low \\
\hline Obidoxime & Low \\
\hline Octreotide & Low \\
\hline Penicillamine & Low \\
\hline Physostigmine & Low \\
\hline Phytomenadione & Low \\
\hline Protamine sulfate & Low \\
\hline Prussian blue & Moderate \\
\hline Pyridoxine injection & Low \\
\hline Silibinin & High \\
\hline Sodium calcium edetate & Moderate \\
\hline Sodium sulfate & Low \\
\hline Sodium thiosulfate & Moderate \\
\hline Vipera berus antivenom (ViperaTAb ${ }^{\circledR}$ ) & High \\
\hline
\end{tabular}

aDimercaptopropanesulphonate (DMPS)

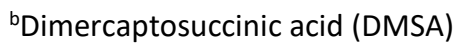




\section{DISCUSSION}

The antidote availability in Norwegian hospitals still varies a lot, and only $22 \%$ of hospitals have stocks compliant with national recommendations. Frequently used antidotes are available in all hospitals, whereas those used more rarely are less available or in too small quantities to treat a single patient.

Lack of guidelines was suggested as a possible cause for poor antidote preparedness in Norway after the survey in $2000^{14}$. Studies from Canada and UK have suggested the same ${ }^{3,7}$. Our survey show that the antidote preparedness is still unsatisfactory and that hospitals are not compliant with national recommendations. There can be several reason for this poor compliance. One probable cause is the lack of clear definition on what characterizes small and large hospitals in the recommendations. Previously, Norwegian hospitals were organized as local, central and regional hospitals. These terms are no longer in use and this classification is therefore likely outdated. Other international guidelines focus predominantly on the timely availability of antidotes ${ }^{9,12,13}$. This requires a critical evaluation of the efficacies of the different antidotes and the need for prompt administration ${ }^{18}$. In the preparation of a preparedness plans, it is essential to know whether the treatment is time-critical and where to get hold of additional supply in short notice. As would be evident in many countries, some regions in Norway have a long transporting time to hospital and between hospitals, and air transport is difficult because of challenging weather conditions. Another element to be considered in the risk and vulnerability analyse, is the opening hours of the hospital pharmacies with regard to get hold of antidotes hospitals nearby don't stockpile or refill of used antidotes. In Norway, they have limited opening hours and are closed during weekends and holidays. Some hospitals have a pharmacist on call when the pharmacy is closed, but this differs between the various regions.

Drug costs has been mentioned as another possible cause why hospitals do not stockpile recommended antidotes $^{4,6,19}$. Treatment with Digoxin immune Fab is a typical example (approximately 2500 Euro for one $40 \mathrm{mg}$ vial), and being stockpiled by only half of the large hospitals. In spite of the price aspect, we found that even cheap antidotes (sodium sulfate and cyproheptadine) were among the least available in small and large hospitals. The cost to treat one $70 \mathrm{~kg}$ patient is below 150 Euro. Similar have been found in Australia and British Columbia ${ }^{5,8}$. Shelf-life is another factor to consider together with costs, and whether agreement exists for replacement after expire date. The latter varies between countries ${ }^{20}$, and for the antidotes in this survey no agreement for replacement after expiry date in Norway exists. 
There are several aspects to the cost; the direct cost of the antidote, and the potential added cost based on the choice of the alternative antidotes. This is illustrated by the use of fomepizole vs. ethanol for toxic alcohol poisonings, where the cost of the antidote not at all reflects the total costs, and thus should be taken into consideration: Ethanol and fomepizole have "equal" effect against toxic alcohols given optimal circumstances, but ethanol has adverse effects on the central nervous system and require frequent therapeutic drug monitoring ${ }^{21}$. International treatment guidelines therefore recommend fomepizole as the antidote of choice ${ }^{21}$, corresponding to the guidelines for antidote stocking in hospitals in UK and US ${ }^{12,13}$. According to our national recommendations all hospitals are supposed to have IV ethanol. Large- and regional hospitals are supposed to stockpile both IV ethanol and fomepizole. IV ethanol is expensive in Norway and the price for a vial of $50 \mathrm{ml} 70 \%$ alcohol is approximately 150 Euro. Using fomepizole may also reduce the need for intensive care beds, which will have a dramatic impact of the overall cost. Further, the need for dialysis can be postponed or even eliminated, and the patients are not drunk, requiring less nursing staff ${ }^{21}$.

Some novel antidotes are not yet part of our recommendations, partly because of the cost: Antidotes against direct oral anticoagulants are among the latest antidotes on the market. Idarusizumab against dabigatran was approved in Europe in 2015, and included in our national recommendations in June 2016. Andexanet alfa the newest antidote approved in Europe last year, is not yet marketed in Norway. These antidotes scores high on the efficiency scale, but the costs for andexanet alfa are between $29040-58080$ USD (26 $400-52800$ EUR) for one patient treated ${ }^{22}$. This is a significantly higher costs than all the other antidotes in our recommendations. The studies also lack a control group, have surrogate endpoints and some have questioned if this correlates to clinical improvement ${ }^{22,23}$. These are consideration to think about when evaluating what to stockpile.

When comparing the Norwegian guidelines with international ${ }^{12,13}$, the main difference is that they are based on the timely availability of the antidote, instead of hospital size. They are also clear on what is the preferred antidote where there are several treatments options, for example fomepizole against toxic alcohol poisoning and hydroxocobalamin against cyanide. Our guidelines on the other hand are not entirely clear here since large- and regional hospitals are recommended to stockpile all treatments options. The most commonly used antidotes that all Norwegian hospitals stockpile are also recommended in international guidelines. On the other hand, sodium sulfate and ipecac syrup that are recommended in all Norwegian hospitals are not included in these international guidelines. These are rare antidotes used in special circumstances. Ipecac syrup is only exceptionally used in children in the 
prehospital setting when transportation time to hospital is long. Sodium sulfate against barium poisoning is not emergency treatment, and only $36 \%$ of all hospitals stockpiled this. The fact that so few hospitals stockpiled this antidote does affect the overall result. Compared to other recommendations, these antidotes are not recommended to be immediately available, it should therefore be considered whether it is necessary for all hospitals to stockpile this.

There are a few antidotes against internal contamination with radioactive materials, but these are not mentioned in our national recommendations. Prussian blue are only recommended for thallium poisoning and not cesium-137. In 2017 national guidelines for handling CBRNE incidents involving personal injury was published and regional stockpiling of Prussian blue and DTPA were recommended ${ }^{24}$. They should therefore also be included in the national recommendations for stockpiling of antidotes in hospitals.

Drug shortage has been a repeated problem worldwide recent years. The delivery situation in Norway is particularly vulnerable since almost half of the antidotes are not licensed in our country. A drug shortage will be discovered late, and worst case scenario have an important impact on patient care and outcome. Taking this into consideration and the fact that only $22 \%$ of hospitals are compliant with the recommendations one should now consider whether today's recommendations should be revised to comply with international guidelines. In a broader perspective, consensus guidelines may be needed in Europe.

\section{CONCLUSION}

Every country needs to rely on a certain stocking of antidotes for treatment for poisoning, incidents- and disaster preparedness. We found a varying compliance with the national recommendations for hospital storage of antidotes, where a large proportion of small and large size hospitals did not follow them. In a broader perspective one should consider whether it is time for standardized European guidelines, supplied with national recommendations based on local poisoning epidemiology.

\section{Limitations}

This study refers to self-reported data, and hospital stockpiles were not manually counted by researchers. Three reminders were made in response to unanswered questionnaires, which may have led some hospitals to correct their shortcomings in the meantime. Subsequent to this survey, two changes to the national recommendations were 
made for large- and regional hospitals: Levocarnitine against valproic acid and idarucizumab against dabigatran were included in the recommendations.

\section{Acknowledgments}

None

\section{Contributors}

YEL has contributed with idea, study design, data collection, data analysis, data interpretation, literature search, and writing. AG has contributed with study design and writing of manuscript. BJS has contributed with study design and writing of manuscript. DJ has contributed with idea, study design and writing the manuscript. ERN has contributed with idea and writing of manuscript. KEH has contributed with idea, study design, data interpretation and writing. All authors have read and approved the final manuscript

\section{Funding}

None

\section{Competing interests}

None declared

\section{Ethics approval and consent to publication}

Our study does not report on human participants, human data or tissue, According to national regulations it was not necessary for ethics approval by Regional committees for medical and health research ethics. Consent was thus not required.

\section{Data availability statement}

The data can be made available from the main author upon reasonable request. 


\section{REFERENCES}

Ohbu S, Yamashina A, Takasu N, et al. Sarin poisoning on Tokyo subway. South Med J 1997;90: 587-93. Vale JA, Marrs TO, Maynard RC. Novichok: a murderous nerve agent attack in the UK. Clin Toxicol (Phila) 2018;56: 1093-97.

Bailey B, Bussieres J, Dumont M. Availability of antidotes in Quebec hospitals before and after dissemination of guidelines. Am J Health Syst Pharm 2003;60: 2345-49.

Dart RC, Stark Y, Fulton B, et al. Insufficient stocking of poisoning antidotes in hospital pharmacies. JAMA 1996;276: 1508-10.

Nissen LM, Wong KH, Jones A, et al. Availability of antidotes for the treatment of acute poisoning in Queensland public hospitals. Aust J Rural Health 2010;18: 78-84.

Ong HC, Yang CC, Deng JF. Inadequate stocking of antidotes in Taiwan: is it a serious problem? J Toxicol Clin Toxicol 2000;38: 21-8.

Thanacoody RH, Aldridge G, Laing W, et al. National audit of antidote stocking in acute hospitals in the UK. Emerg Med J 2013;30: 393-6.

Wiens MO, Zed PJ, Lepik KJ, et al. Adequacy of antidote stocking in British Columbia hospitals: the 2005 Antidote Stocking Study. Cjem 2006;8: 409-16.

Pronczuk de Garbino J, Haines JA, Jacobsen D, et al. Evaluation of antidotes: activities of the International Programme on Chemical Safety. J Toxicol Clin Toxicol 1997;35: 333-43.

Dart RC, Goldfrank LR, Chyka PA, et al. Combined evidence-based literature analysis and consensus guidelines for stocking of emergency antidotes in the United States. Ann Emerg Med 2000;36: 126-32. Dart RC, Borron SW, Caravati EM, et al. Expert consensus guidelines for stocking of antidotes in hospitals that provide emergency care. Ann Emerg Med 2009;54: 386-94.e1.

Dart RC, Goldfrank LR, Erstad BL, et al. Expert Consensus Guidelines for Stocking of Antidotes in Hospitals That Provide Emergency Care. Ann Emerg Med 2018;71: 314-25.e1.

Royal College of Emergency Medicine and National Poisons Information Service. Guideline on Antidote Availability for Emergency Departments January 2017. Available:

https://www.rcem.ac.uk/docs/College\%20Guidelines/RCEM\%20NPIS\%20Antidote\%20Guideline\%20List.pdf [Accessed 4 Feb 2020].

Solheim L, Andrew E, Jacobsen D. Antidote availability in Norway. Tidsskr Nor Laegeforen 2002;122: 1111-3. Centers for Disease and Control and Prevention: DTPA (Diethylenetriamine pentaacetate). Available: https://www.cdc.gov/nceh/radiation/emergencies/dtpa.htm [Accessed 4 Feb 2020].

\section{World Health Oranization: Development of stockpiles for radiation emergencies. Available:}

https://www.who.int/ionizing radiation/a e/emergencies/WHO stockpile report 2007.pdf Accessed 4 Feb 2020.

Jacobsen D. The relative efficacy of antidotes. J Toxicol Clin Toxicol 1995;33: 705-8.

Jacobsen D, Haines JA. The relative efficacy of antidotes: the IPCS evaluation series. International Programme on Chemical Safety. Arch Toxicol Suppl 1997;19: 305-10.

Woolf AD, Chrisanthus K. On-site availability of selected antidotes: results of a survey of Massachusetts hospitals. Am J Emerg Med 1997;15: 62-6.

Sivilotti ML, Eisen JS, Lee JS, et al. Can emergency departments not afford to carry essential antidotes? Cjem 2002;4: 23-33.

McMartin K, Jacobsen D, Hovda KE. Antidotes for poisoning by alcohols that form toxic metabolites. Br J Clin Pharmacol 2015:

Peled H, Dau NQ, Lau H. Key Points to Consider When Evaluating Andexxa for Formulary Addition. Neurocrit Care 2019:

Godier A, Martin AC. Specific Antidotes for Direct Oral Anticoagulant Reversal: Case Closed or Cold Case? Circulation 2019;140: 1445-47.

National guidelines for handling CBRNE incidents with personal injury. Available:

https://www.helsedirektoratet.no/produkter/ /attachment/inline/9b2099c4-4573-46d8-9260-

227b55714cb9:fac65e34d9d1133b1b8e87f2d7a4f3b1764b7acf/CBRNE-

hendelser\%20med\%20personskade\%20\%E2\%80\%93\%20Nasjonal\%20faglig\%20retningslinje.pdf [Accessed 17 Feb 2020]. 
Atropine (nicotinic features) - LOW

Diazepam (OP poisoning) - LOW

Silibinin - HIGH

\section{DMPS ${ }^{a}$ - MODERATE \\ DMSA $^{\mathrm{b}}$ - HIGH \\ Oximes - LOW}

Sodium thiosulfate - MODERATE

Hydroxocobalamin - HIGH

Atropine (muscarinic) - LOW

Acetylcystein - LOW

Ethanol/Fomepizole - HIGH

Fab fragments - HIGH

Flumazenil - LOW

Naloxone - LOW 